\title{
Near Net Shape Manufacture of Titanium Alloy Components from Powder and Wire: A Review of State-of-the-Art Process Routes
}

\author{
Thomas Childerhouse * and Martin Jackson $\mathbb{D}$ \\ Department of Material Science and Engineering, The University of Sheffield, Sir Robert Hadfield Building, \\ Mappin Street, Sheffield S1 3JD, UK; martin.jackson@sheffield.ac.uk \\ * Correspondence: tchilderhouse1@sheffield.ac.uk
}

Received: 20 May 2019; Accepted: 13 June 2019; Published: 15 June 2019

\begin{abstract}
Near net shape (NNS) manufacturing offers an alternative to conventional processes for the manufacture of titanium alloy components. Compared to the conventional routes, which typically require extensive material removal of forged billets, NNS methods offer more efficient material usage and can significantly reduce machining requirements. Furthermore, NNS manufacturing processes offer benefits such as greater flexibility and reduced costs compared to conventional methods. Processes such as metal additive manufacturing (AM) have started to be adopted in niche applications, most notably for the manufacture of medical implants, where many conventionally forged components have been replaced by those manufactured by AM processes. However, for more widespread adoption of these emerging processes, an improvement in the confidence in the techniques by manufacturers is necessary. This requires addressing challenges such as the limited mechanical properties of parts in their as-built condition compared to wrought products and the post-process machining requirements of components manufactured by these routes. In this review, processes which use a powder or wire feedstock are evaluated to assess their capabilities for the manufacture of titanium alloy components. These processes include powder bed fusion and direct energy deposition metal additive processes as well as hybrid routes, which combine powder metallurgy with thermomechanical post-processing.
\end{abstract}

Keywords: powder metallurgy; metal additive manufacturing

\section{Introduction}

Conventional process routes for manufacturing titanium alloy components in the dominant aerospace sector typically involve extensive subtractive machining of forged billets. It is not uncommon for machining processes to remove $80-90 \%$ of the forging to achieve the final part dimensions, contributing up to $60 \%$ of a component's manufacturing cost [1]. Therefore, near net shape (NNS) manufacturing processes are emerging as alternative methods for the production of a range titanium alloy components. Compared to conventional processes, these methods require significantly less material removal, as parts can be manufactured to geometries which more closely resemble the final component. This means that significantly less machining is required to produce the finished component, resulting in reduced machining costs and a reduced amount of waste material such as machining swarf [2].

Over the last two decades, several alternative process routes have been developed in order to discover the Holy Grail of displacing the Kroll Process to provide low cost titanium. The majority of these alternative titanium extraction processes produce a powder and particulate feedstock $[3,4]$ which has focused researchers to develop low cost downstream powder consolidation processes, in the 
hope that some of these extraction routes can be industrialised. However, today the Kroll Process remains dominant and will remain so for many decades to come. Outside of metal additive processes, there is an increasing research focus towards developing methods that will reuse aerospace recycled powder [5] such as machining swarf and chips [6,7] and the reuse of increasing amounts of surplus or oversized additive manufacturing powder.

For safety critical components, such as large landing gear forgings and compressor discs, Kroll derived product that has been through a vacuum arc remelting and multi-step forging route is unlikely to be displaced by NNS routes directly from powder. However, the potential economic benefits of using NNS powder metallurgy processes to produce non-safety critical titanium components are particularly attractive, as these processes can make titanium alloys more economically viable for the non-aerospace industries, which seek to utilise the excellent strength to weight and corrosion resistant properties offered by the material. Furthermore, the implementation of NNS processes for the manufacture of aerospace components has the potential to reduce manufacturing costs associated with titanium for the aerospace industry [8].

There are currently a variety of NNS manufacturing processes available, which can be grouped in to the following families: metal additive manufacturing (AM) and hybrid processing routes. At present, these processes are at different levels of technology readiness, ranging from early developmental stages to being used for niche component manufacture [9]. The authors are currently investigating the potential benefits and challenges of a range of emerging processing routes for the manufacture and finish machining of small scale components, such as the valve train rocker arms shown in Figure 1. Figure 2 summarises the new and emerging process families which are reviewed in this paper and shows technologies and examples of applications associated with each process. The authors recommend a recent review by Fang et al. [4] for the more traditional pressing and sintering consolidation processes for titanium powders. Furthermore, hot isostatic pressing (HIPing) [10,11] vacuum hot pressing (VHP) and metal injection moulding (MIM) [12], which are long established consolidation routes for titanium alloy powders, are outside of the scope of this review. Investment casting technology [13] and superplastic forming of sheet [14] are also established non-powder techniques used to manufacture NNS titanium alloy components and are also beyond the scope of this review.

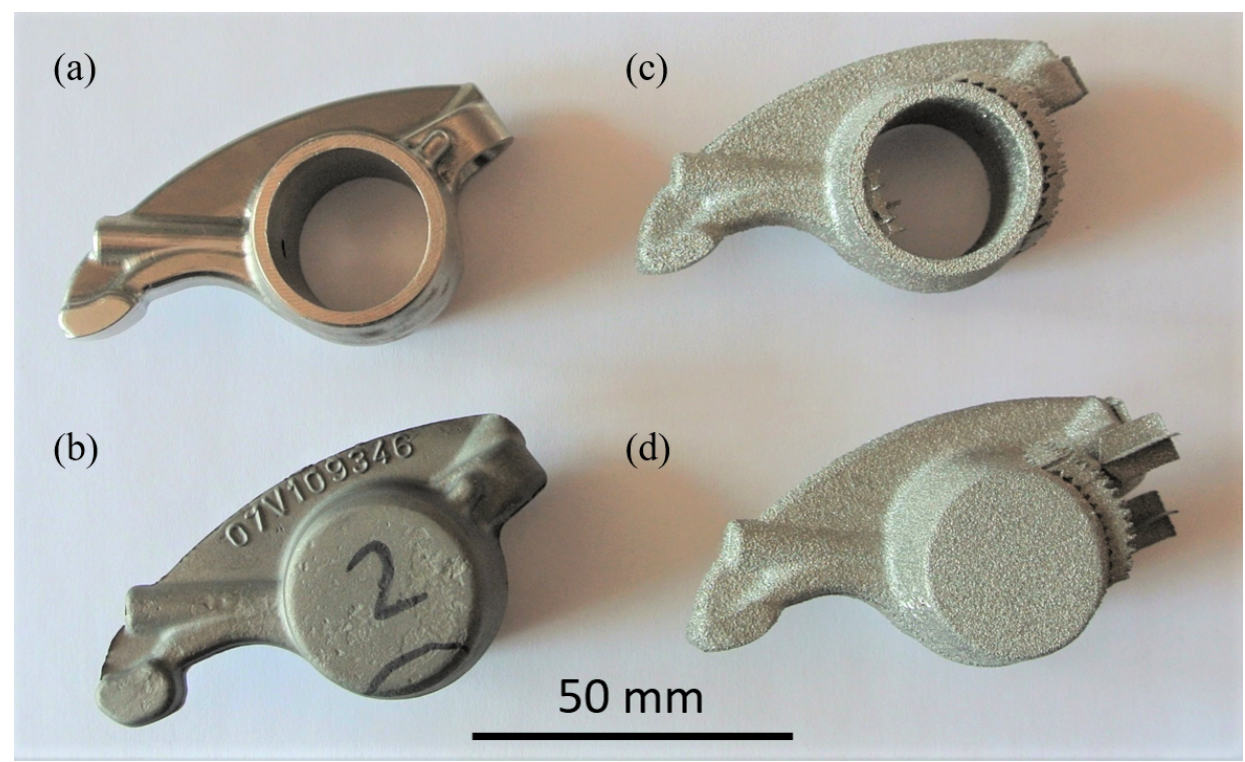

Figure 1. Ti-6Al-4V valve train rocker arms manufactured through the University of Sheffield by the following metal additive and hybrid powder metallurgy process routes: (a) FAST-forge with post-process finish machining; (b) FAST-forge; (c) SEBM metal additive; and (d) SEBM metal additive with additional machining stock. The forging of the FAST-forge components $(\mathbf{a}, \mathbf{b})$ was carried out by Victoria Forgings, Wolverhampton. 


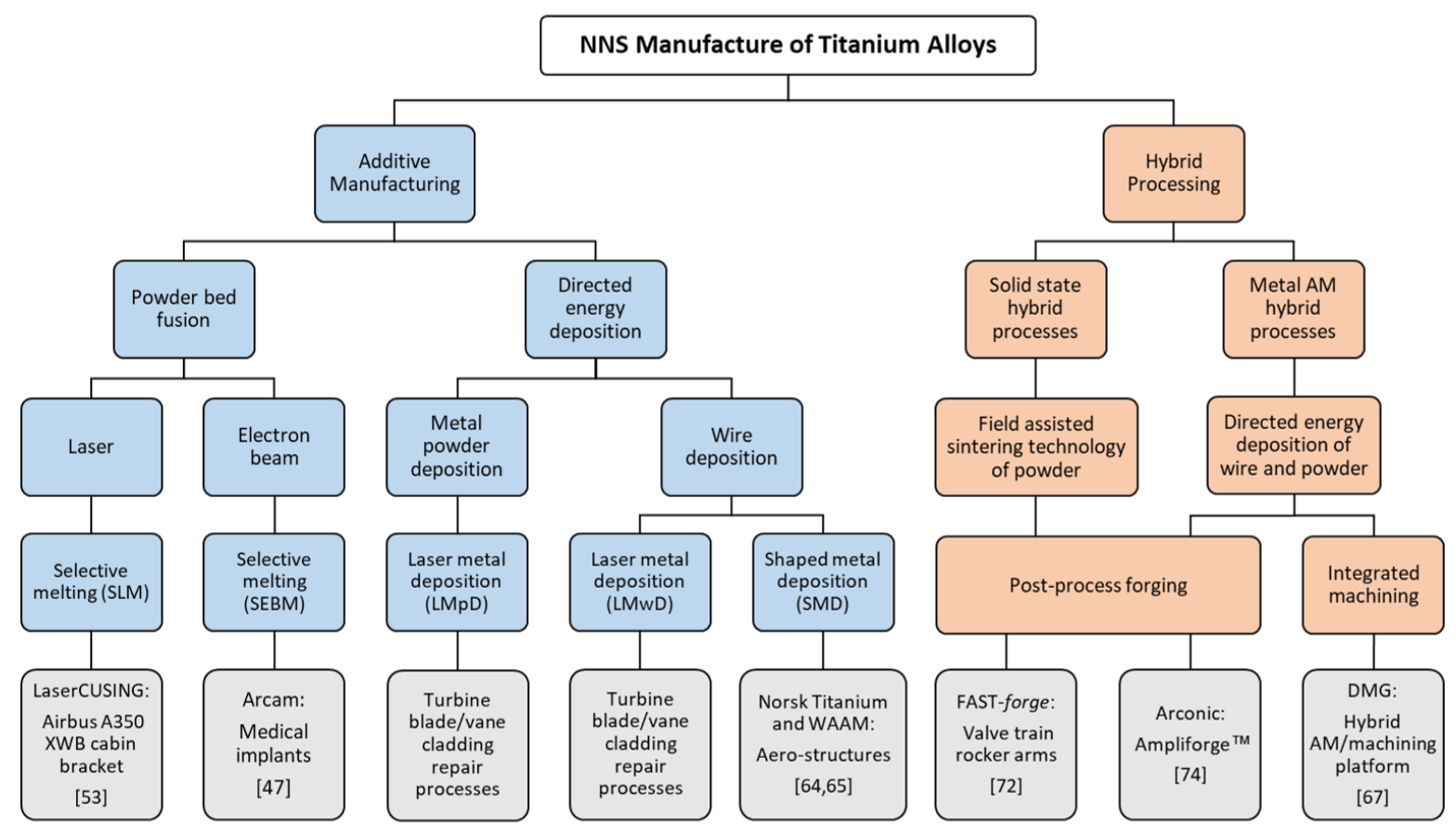

Figure 2. A schematic summary of emerging NNS manufacturing methods suitable for the manufacture of titanium alloys components from powder and wire feedstocks.

Metal AM processes involve the fabrication of components one layer at a time based upon cross sectional layers taken from a CAD model of the component. These processes differ to subtractive manufacturing methods, as components are built up gradually, layer upon layer, rather than by removing material from a billet or forging. Currently, metal AM of titanium alloys has seen significant use in the medical industry for the manufacture of implants $[15,16]$. In these applications, the capabilities of metal AM for manufacturing highly complex geometries and the flexibility of AM processes in manufacturing bespoke components for individual patients means that AM is much better suited than conventional manufacturing methods. In the aerospace industry, metal AM has started to be adopted for the manufacture of components such as brackets [17]. In these types of applications, the suitability of AM for the production of parts with topologically optimised designs is advantageous, as lighter weight components are achievable when using these methods. Hybrid processing routes involve thermomechanical post processing of parts manufactured by NNS methods to enhance the mechanical properties of the part. The development of these types of processes has been motivated by the need to improve the mechanical properties of NNS components in their as-built condition, which is typically inferior to forged material and therefore makes these components unsuitable for structurally critical applications [18].

This review summarises the state of the art of emerging NNS manufacturing processes which are suitable for the production of titanium alloy components. Examples of recent component specific developments for each of the emerging process have been provided to demonstrate the unique benefits they offer as well as their limitations. The technologies considered in this review include both powder bed fusion and directed energy deposition metal AM processes. Novel hybrid processes which use a post-process hot forging step to enhance the mechanical properties of parts produced by AM and solid state routes have also been reviewed to highlight their potential for manufacturing structurally critical components. 


\section{Additive Manufacturing Processes}

Various metal AM methods exist which can be used for the manufacture of titanium alloy components. Compared to conventional processes, these methods offer benefits such as greater manufacturing flexibility, the ability to manufacture components with more complex geometries and hollow features, as well as greater control over the material properties [9]. These benefits, as well as the advantage of the reduced requirement for material removal, makes metal AM an attractive option for many applications. Metal AM methods are often insufficient, however, for producing components with a high enough dimensional accuracy and surface finish quality for many applications and so post-process machining operations are usually required to produce the final component [19]. The most popular metal AM processes in applications using titanium alloys use either powder bed fusion (PBF) or directed energy deposition (DED) methods to build the component. Powder bed fusion methods use either a laser or electron beam power source to fuse particles of metal together [20], whereas directed energy deposition methods deposit a melted material feedstock through a nozzle onto a surface. This feedstock can consist of a powder, wire, or a combination of both [21]. In applications where higher deposition rates are important, such as for the manufacture of larger components, DED methods are preferred due to the much slower build rates achievable with PBF. PBF methods, however, are advantageous in comparison to DED methods in their ability to manufacture parts with a better resolution and surface quality [22].

Figure 3 shows a schematic representation of both PBF and DED metal AM processes highlighting the differences between the two techniques. In this review, the technologies using a PBF method which have been considered are selective laser melting (SLM) and selective electron beam melting (SEBM). The technologies considered using DED are laser metal powder and wire deposition (LMpD/LMwD) and shaped metal deposition (SMD) processes.
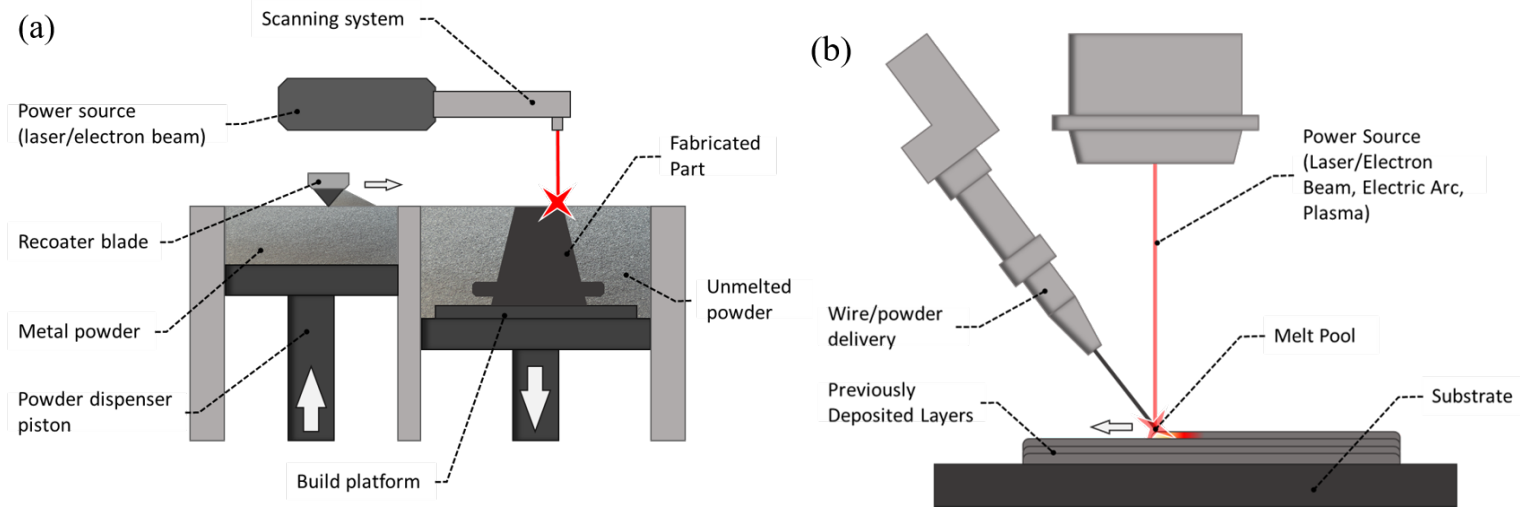

Figure 3. Schematic representation of: (a) powder bed fusion; and (b) directed energy deposition metal additive manufacturing processes.

\subsection{Limitations of Metal AM for Titanium Alloy Components}

The main limitation of components produced by metal AM is a lack of knowledge of the mechanical properties for a given component. There are many parameters related to the build process which influence the microstructure of the as-built material, and thus the mechanical properties of the component. Although properties such as the yield and ultimate tensile strength of AM Ti-6Al-4V, for example, are similar to those of wrought material, other properties, such as the fatigue strength and ductility of AM titanium alloys are often inferior to forged material and are typically more similar to those of cast material [23]. Therefore, applications for titanium components built using metal AM are generally well suited for replacing cast components, rather than critical structural components, which require the superior mechanical properties achieved by the forging process.

Mechanical properties of AM titanium are dependent on both the microstructure and the occurrence of metallurgical defects which may be present within the material. Both of these are 
affected by the thermal effects of the AM process on the material [22]. Porosity related defects are more common in PBF processes and these defects are detrimental to fatigue performance. The defects most commonly observed in AM titanium are irregular shaped pores (shown in Figure 4a), caused by a lack of fusion between particles due to insufficient melting and spherical pores (shown in Figure 4b). These are caused by gas entrapped within the powder feedstock. The occurrence of these types of metallurgical defects are dependent on both the AM process parameters selected and the quality of the metal powder or wire feedstock [23]. Moreover, the distribution of defects is also an important consideration, as non-uniformly distributed defects within the part are more of a concern for the integrity of the component. Defects distributed in the sub-surface of the part, for example, are at risk of being exposed in any post-process machining that may be carried out and reveal crack initiation sites at the component's surface. Work carried out by Tammas-Williams et al. [24] has indicated that the beam strategies used in SEBM processes influence the distribution and type of pores found in Ti-6Al-4V additive material. Notably, lack-of-fusion defects were found to be more concentrated in the sub-surface of the part in the contoured region, whereas gas-entrapped pores were found to be concentrated towards the centre of the part in the hatched region.

Compared to conventional manufacturing processes, there is less knowledge about the effects of the AM process on the component's microstructure. During the metal AM process, the material is subject to both high temperature gradients and complex thermal histories which influence the microstructure of the built component. Furthermore, the build process parameters selected also have an influence on the microstructure of the material due to their effects on the thermal history during the process. Therefore, the study of the microstructure of AM titanium material has been an area which has seen significant research [25-28].

During the AM process, the melting of the feedstock material to form the melt pool requires the heating of titanium alloys to above the $\beta$ transus temperature. This results in a phase change of the material to the $\beta$ phase. Upon cooling, solidification of the molten alloy results in the formation of a macrostructure comprised of both equiaxed, as well as columnar, prior $\beta$ grains. During solidification, prior $\beta$ grains grow epitaxially to form columnar $\beta$ grains. These grains are aligned in the build direction, as this corresponds with the direction of the maximum thermal gradient that occurs during the build process. As the material cools below the $\beta$ transus temperature, the $\beta$ to $\alpha$ phase transformation occurs. Depending on the solidification rate, $\alpha$ phase forms at either the prior $\beta$ grain boundaries or martensitic $\alpha^{\prime}$ laths grow inside the prior $\beta$ grains [29]. At the high cooling rates, typical in many AM processes, nucleation of $\alpha$ phase at both the grain boundaries and within the prior $\beta$ grains occurs simultaneously, resulting in a basketweave or Widmanstätten morphology, which is typical of most AM Ti-6Al-4V material [30]. The grain morphology and grain size, as well as the ratio between columnar and equiaxed $\beta$ grains and the ratio of $\alpha$ and martensitic $\alpha^{\prime}$ is dependent on the cooling rate. Higher cooling rates result in the formation of a higher ratio of equiaxed $\beta$ grains and $\alpha^{\prime}$ martensite, whereas slower cooling rates will result in a higher ratio of columnar $\beta$ and $\alpha$ grains [22].

Figure $4 \mathrm{c}-\mathrm{h}$ shows microstructures of Ti-6Al-4V material produced by a variety of AM processes. Titanium is an allotropic metal with an $\alpha$ to $\beta$ transformation at approximately $980{ }^{\circ} \mathrm{C}$ in Ti-6Al-4V. The range of microstructures in Figure $4 \mathrm{c}-\mathrm{h}$ show predominantly $\alpha$ phase microstructures at room temperature, yet the different cooling rates of the AM routes produce different morphologies. A basketweave morphology comprised of intertwined $\alpha$ platelets develops in material from SLM, SEBM, and SMD processes, whereas the faster cooling rates in LMpD process develops a fine-scale, acicular $\alpha$ martensite structure. For the LMwD process, two different microstructures are shown to highlight the effects of dwell time between deposited layers. When layers are deposited with no dwell time (LMwD-0) the cooling rate is slow enough for the growth of parallel $\alpha$ platelets to occur and form a Widmanstätten morphology. These ordered $\alpha$ platelets are often referred to as $\alpha$ colonies and are highlighted by the white dotted lines in Figure 4e. When a two minute dwell time between layer deposits is employed (LMwD-2) the cooling rate is too rapid for the formation of $\alpha$ colonies and instead a more finely grained basketweave morphology of intertwined $\alpha$ platelets is formed [29]. 

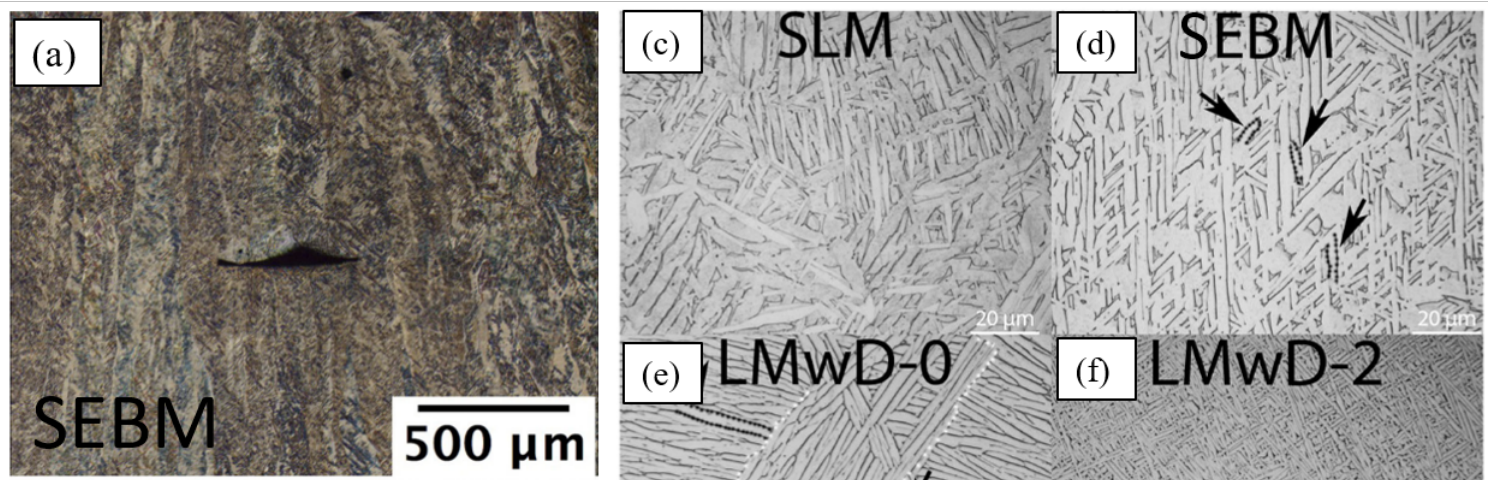

(f) $\mathrm{LMwD}-2$
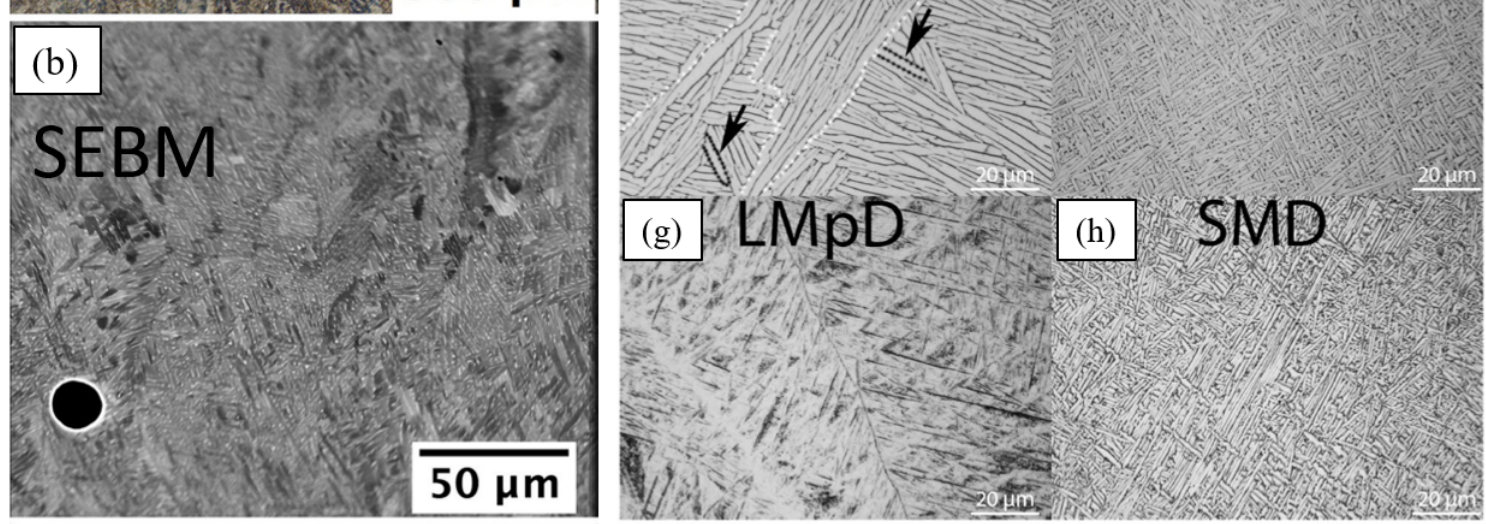

Figure 4. Microstructural features of SEBM additive Ti-6Al-4V: (a) irregular pore attributed to lack of fusion; and (b) spherical pore attributed to gas trapped within the powder feedstock. Microstructures of Ti-6Al-4V showing a basketweave type structure produced by the following additive processes: (c) SLM; (d) SEBM; (f) LMwD (with a 2-min dwell time between deposited layers); and (h) SMD. Ti-6Al-4V produced by: (e) LMwD (with no dwell time between sequentially deposited layers) showing a Widmanstätten type structure; and (g) LMpD showing a martensitic structure. In (c-h). the residual $\beta$ phase appears dark between the $\alpha$ platelets. Images in $(\mathbf{a}, \mathbf{b})$ and $(\mathbf{c}-\mathbf{h})$ reproduced with permission from Cunningham et al. [31] and Neikter et al. [29], respectively.

Table 1 gives a range of typical values for the mechanical properties of Ti- $6 \mathrm{Al}-4 \mathrm{~V}$ produced by different AM techniques that are reported in the literature. For each of the AM processes, a wide range of mechanical properties are attainable. These properties are dependent on the microstructure, defects, and residual stresses within the material and are influenced by different build parameters, part orientation and location, feedstock quality, and machine selection [32]. The high number of influencing factors has led to a high range in the values of mechanical properties reported for a given technique and this makes it difficult to directly compare the mechanical properties of materials produced by the different methods. The results in the table indicate that the yield strength and the UTS of AM Ti-6Al-4V can exceed the ASTM requirement for wrought Ti- $6 \mathrm{Al}-4 \mathrm{~V}$. This is due to the fine grained $\alpha$ microstructure typical in the material. However, this mechanical performance often exhibits directional dependence due to the the columnar nature of the microstructure [29]. Both the finely grained $\alpha$ microstructure and the presence of porosity related defects also results in poor ductility and fatigue performance of the material in its as-built condition compared to wrought Ti-6Al-4V [32,33].

In addition to the effects on the microstructure, the highly localised temperatures involved in the AM process also has an affect on the formation of residual stresses within the component, due to the temperature induced strain mismatch that occurs from the high thermal gradients [34]. Compressive residual stresses are generated in AM materials due to the constraints on thermally expanding material by surrounding cooler material, whereas tensile stresses can be generated as contracting material is restricted as it cools [21]. Furthermore, these thermal effects can also contribute to part distortion. 
Table 1. A summary of reported mechanical properties of Ti-6Al-4V material manufactured using different AM process routes. Data taken from Lewandowski and Seifi [32] and Baufeld et al. [35].

\begin{tabular}{|c|c|c|c|c|}
\hline Process Route & Condition & Yield Strength (MPa) & $\mathrm{UTS}^{\mathrm{a}}$ (MPa) & Elongation (\%) \\
\hline \multirow[t]{3}{*}{ SLM } & As built & $736-1166$ & $1035-1407$ & $1.6-12$ \\
\hline & Heat treated & $862-1145$ & $936-1228$ & $7-12$ \\
\hline & $\mathrm{HIP}^{\mathrm{b}}$ & 835-973 & 910-1088 & 5-19 \\
\hline \multirow[t]{3}{*}{ SEBM } & As built & $782-1150$ & $775-1237$ & $2.3-17$ \\
\hline & Heat treated & 869 & 965 & 6 \\
\hline & HIP & $795-876$ & $870-978$ & $13-20$ \\
\hline \multirow[t]{3}{*}{ LMD } & As built & 908-1105 & $1025-1163$ & $3.8-14$ \\
\hline & Heat treated & $832-1066$ & $832-1112$ & $0.8-16$ \\
\hline & HIP & $850-952$ & 920-1007 & $11.8-17$ \\
\hline SMD [35] & As built & NA & $936-1014$ & $5.1-19$ \\
\hline ASTM & Wrought & $>860$ & $>960$ & $>10$ \\
\hline Requirement ${ }^{c}$ & Cast & $>758$ & $>860$ & $>8$ \\
\hline
\end{tabular}

To improve the mechanical properties of AM titanium in the as-built condition, post processing such as heat treatments or HIPing can be carried out. The effects of these post-process treatments on the mechanical properties of AM Ti-6Al-4V are shown in Table 1 . Heat treatments are often carried out to both refine the microstructure of the material and to relieve residual stresses, resulting in parts with enhanced ductility and fatigue strength compared to material in the as-built condition [36]. HIP has been demonstrated to reduce the porosity of AM titanium parts by eliminating lack-of-fusion defects and gas entrapped pores. This improves the ductility and fatigue strength of the material and reduces levels of anisotropy [34].

The high affinity for oxygen is another concern for metal AM with titanium alloys. Both the pick-up of oxygen during the build process as well as the the oxygen content in the starting feedstock material can result in nucleation sites for pore formation during the build process [37]. The formation of such pores can have detrimental effects to the ductility and fatigue properties of the component produced [23]. During the build process, the elevated temperatures make the material particularly susceptible to oxidation and this requires processes to be carried out within an inert atmosphere to prevent oxidation of the material [18]. In DED processes, shielding with an inert gases, such as argon, is used to prevent oxygen and nitrogen exposure with the hot material. In these processes, oxide contamination of the Ti-6Al-4V has been shown to cause both oxide scale as well as the formation of a brittle oxygen-enriched $\alpha$ layer (often referred to as $\alpha$ case) near the component's surface [38]. Studies have shown that parameters such as long exposure times and high processing temperatures can lead to deeper oxygen penetration in the material. In these conditions, the depths of penetration of the oxygen-enriched layer have found to reach up to $200 \mu \mathrm{m}$, whereas typical processing conditions have been shown to result in oxygen penetration to less than $100 \mu \mathrm{m}[38,39]$. In any case, the oxidation of the material has not been found to penetrate into the bulk of the material and therefore post-process machining of the as-built component would be sufficient to remove the oxygen-enriched layer.

SLM processes also use argon gas to prevent oxidation during processing. However, unlike DED the process takes place within an argon filled chamber rather than using a localised shielding gas. In SLM, the level of oxidation to the material has been found to be dependent on the laser beam power, with higher laser power resulting in more oxidation and a hardness increase in the material [40]. During SEBM, vacuum chambers are used to prevent oxygen exposure. The surface oxide thickness of Ti-6Al-4V samples produced by SEBM has found to be dependent on the orientation and location of the surface within the build [41]. In PBF processes, it is necessary to recover the un-melted powder for use in following build processes to ensure that the material is not wasted. It has been found that increasing the number of times titanium powder is reused in this manner has a significant effect on its 
quality and results in an increased oxygen content [42]. This increased oxygen content has been found to have implications on the mechanical properties of the part, notably an increase in yield strength and UTS but a reduced ductility [43]. Unlike PBF processes, DED processes do not rely on reuse of the starting material and are therefore not susceptible to oxygen pick-up from reuse but are still affected by the oxygen content in the virgin feedstock material [39].

\subsection{Selective Laser Melting}

SLM is a powder bed fusion process which uses laser beam energy to melt metal powder particles into a liquid pool which quickly solidifies, consolidating the material together and forming the component. The component is built by scanning the laser spot over the desired cross-sectional area of the component in the powder bed. This process consolidates the material layer upon layer until the desired component geometry is achieved [44]. The use of SLM processes for the manufacture of titanium components has begun to be adopted in both aerospace and medical applications [20,45]. Figure 5a shows a titanium cabin bracket built for the Airbus A350 XWB using the SLM process. The geometry of this components is indicative of the topologically optimised geometry that is achievable using SLM processes.

An aerospace application demonstrating the capabilities of the technique is the fabrication of a turbine blade prototype using Ti-6Al-4V powder [46]. In this work, it is demonstrated how the design and positioning of support structures, as well as the orientation of the part on the build platform, influence the thermal strains induced in the component. Additionally, the positioning of support structures on critical surfaces of the aerofoil was also avoided to improve the finish of these surfaces. These are examples of additional build parameters which are also important considerations for AM using PBF methods and are specific to the geometry of the part being built. Geometrical distortion was measured in the prototype blade produced in the study, which was attributed to bulging and delamination of the part. This suggests that post-process machining could be used in following the SLM process to manufacture components with improved geometrical tolerances.

SLM processes are currently being used in the medical industry for the manufacture of implants [47]. These types of components are often manufactured using titanium alloys such as Ti-6Al-7Nb and Ti-42Nb, as, along with excellent biocompatibility, these alloys process elastic moduli which allow implants to be manufactured which closely resemble the properties of trabecular bone [20,48]. Furthermore, the capabilities of the SLM process for manufacturing complex geometries makes it an ideal for building honeycomb type structures. This allows the porosity of components to be controlled by altering build parameters and therefore, implants can be built to have a porosity architecture similar to that of trabecular bone which improves bone tissue ingrowth within the implant [49]. With conventional manufacturing methods, building such structures is not possible. Therefore, SLM offers significant advantages over conventional methods for the manufacture of medical implants.

The post-process finish machinability of SLM parts has been investigated in a number of studies [50-52]. Shunmugavel et al. [50] found that SLM Ti-6Al-4V was more challenging to machine than its wrought counterpart. Both cutting forces and wear rates of a PVD coated tool were found to be significantly greater for the SLM material. This was attributed to the material properties of the SLM material being both harder and of higher strength than the wrought material. In the study by Milton et al. [51], higher axial cutting forces were also demonstrated in the machining of SLM Ti-6Al-4V compared to the wrought material. Discontinuities in the hardness of the SLM workpiece material was the suggested reason for the increased cutting forces. 

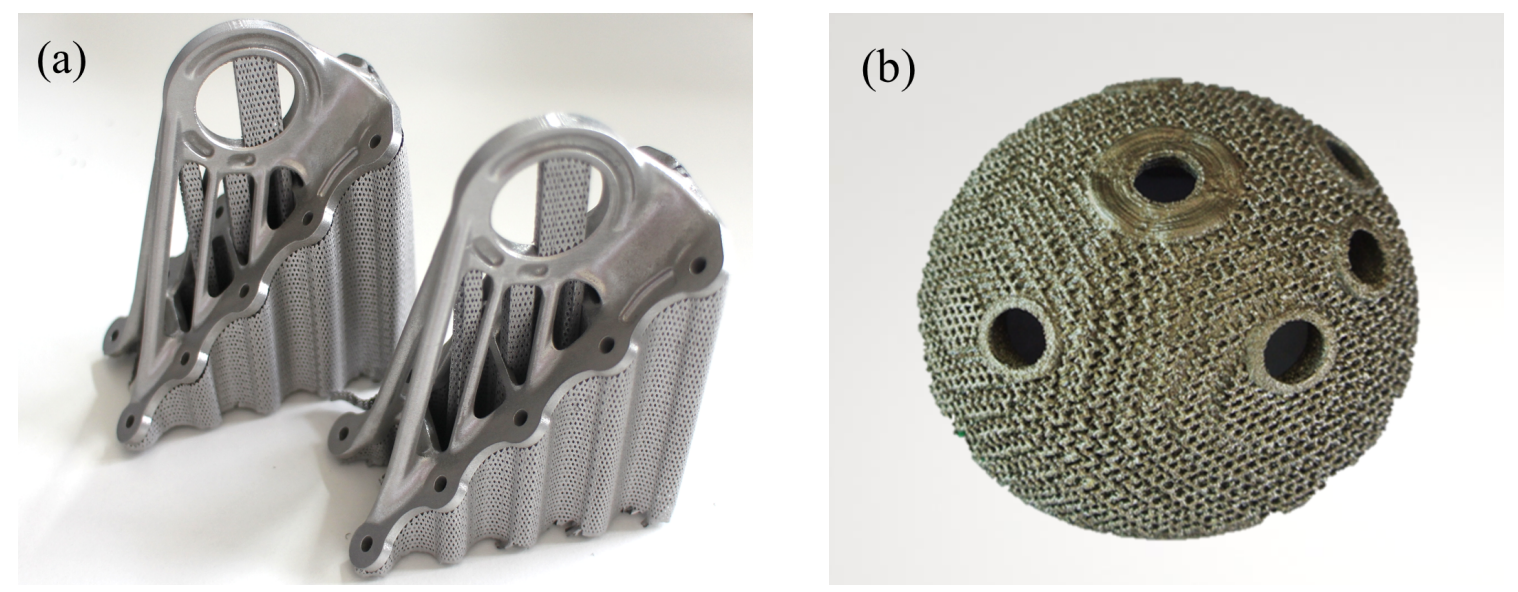

Figure 5. Titanium components manufactured by powder bed fusion metal additive manufacturing processes: (a) Airbus A350 XWB cabin bracket built by GE Additve's LaserCUSING ${ }^{\circledR}$ SLM additive manufacturing process. (b) Medical implant built using Arcam's SEBM technology at the University of Sheffield. Image in (a) reproduced with permission from GE Additive Concept Laser [53].

\subsection{Selective Electron Beam Melting}

In SEBM, the laser beam energy source that is used for SLM is replaced by that of an electron beam [54]. Compared to SLM methods, somewhat higher build rates are achievable (up to $100 \mathrm{~cm}^{3} / \mathrm{h}$ compared to $70 \mathrm{~cm}^{3} / \mathrm{h}$ ) and generally the process is capable of producing fully dense components with fewer defects compared to SLM [55]. The surface finish of components produced by SEBM however, are considered to be of a lower quality [22]. Compared to SLM, where rapid cooling rates induce displacive martensitic transformations from the $\beta$ phase, microstructures in SEBM titanium builds are dominated by diffusional transformations of elongated $\alpha$ and far less $\alpha^{\prime}$ in prior $\beta$ grains (in the case of Ti-6Al-4V). This is due to the slower cooling rates and the fact that the build is maintained at a higher temperature during the SEBM process. This is advantageous for the mechanical properties of components produced by SEBM, as lower levels of anisotropy and residual stress are typical, as the part is annealed during the process [55]. For this reason, post-process heat treatments are generally not required for SEBM parts.

SEBM has been used as an alternative method to machining wrought Ti-6Al-4V material to produce a variety of brackets in a spacecraft application [56]. In this application, parts were designed to have additional bulk to allow for machining of the as-built part in order to produce finished components which met the necessary tolerances. In the project, the SEBM/machining process route was found to offer various benefits compared to machining wrought material. These advantages included much reduced manufacturing lead times, which allowed for the manufacture of a number of complex designs and lower costs compared to the conventional route. The properties of the components built were found to be nearly equivalent to the wrought parts they replaced. Similar to SLM, SEBM is an AM process capable of producing medical implants such as those shown in Figure 5b. Like SLM processes, SEBM has similar capabilities in producing implants with the porosity and mechanical properties that mimic trabecular bone and also offers significant advantages compared to conventional manufacturing methods for these types of components [47].

The challenges involved in the post-process machining of SEBM and SLM Ti-6Al-4V parts were investigated by Sartori et al. [57]. In this work, both cryogenic coolant and dry-cutting strategies were investigated. These refrain from using traditional coolants, which are less preferable when manufacturing biomedical implants due to the potential for contamination of the component with toxic substances. The study shows that the wear on both the crater and the flank was highest when machining the material produced by the SLM process, which was followed by the wrought material. The material produced by SEBM proved to have better machinability characteristics compared to the wrought equivalent. The difference in tool wear when machining the various materials was attributed 
to the effects of material hardness and thermal conductivity of the workpiece material on the tool wear mechanism. The SLM material possessed both the highest hardness and lowest thermal conductivity of all the materials investigated and this resulted in this material being the most challenging to machine. The investigation also demonstrated the effectiveness of the use of cryogenic cooling at reducing cutting temperatures compared to dry cutting. The use of the liquid nitrogen coolant was successful in reducing flank wear of the tool and almost eliminated crater wear entirely.

\subsection{Directed Energy Deposition}

The DED process, schematically represented in Figure $3 b$, involves the delivery of either a wire or powder feedstock into a melt-pool on the surface of a substrate material. The feedstock melts and contributes to the volume of the pool. The component is then cladded layer by layer, as the melt-pool solidifies and the process is repeated on the newly built layer [21]. Various DED technologies exist which use different energy sources for melting the feedstock material. In LMD processes, high-power laser beams are used to provide the energy required to melt the substrate and feedstock material. The beam is directed along the surface of the substrate to follow the path of the desired component's cross-section. In laser metal wire deposition (LMD), the feedstock can consist of either a wire or powder, with wire being advantageous in terms of lower costs, ease of handling, and its ability to achieve higher deposition rates [58]. Material delivery can be carried out by either a single nozzle or, alternatively, multiple nozzles can be used to combine different feedstock materials, such as different powders, or a combination of both powder and wire can be used [59]. The use of combined feedstock materials offers the ability to achieve greater control over the properties of the built material by alloying materials in the melt pool, or can be used for the production of functionally graded components [60].

For SMD processes, wire feedstocks are used and the laser energy source is replaced by either electric arc welding or a plasma process. However, similar to LMD processes, the method of cladding a new layer of material upon a previously deposited layer remains the same [61]. Compared to LMD, these methods offer less control over the thermal heat input to the feedstock and therefore are more prone to excess heat input leading to thermal distortion and oxidation of the material [2].

Compared to powder bed processes, in particular SLM, DED processes involve much larger volumes of material and the scanning speed of the energy source is much slower. As such, DED processes have considerably slower cooling rates of the deposited material. This means that more coarsely grained microstructures with a reduced $\alpha^{\prime}$ content are attainable using DED methods and parts produced are generally more ductile, but lower in strength than SLM material [62].

\subsection{Blown Powder Directed Energy Deposition}

Metal powder DED processes are often referred to as blown powder processes. Clark et al. [63] used a LMpD process to fabricate thin walled parts representative of the types of component geometry typical of aerospace structures. In this application, a blown powder process was selected rather than a wire fed DED process due to the better capability of producing thin walled components featuring sharp corners when using a powder feedstock. Microstructural evaluation of the part showed grain elongation in the build direction due to epitaxial prior $\beta$ grain growth in this direction and the microstructure was found to be more consistent at different locations of the part than a similar cast component. Furthermore, the project highlighted the requirement for post-process machining of the AM part to remove geometrical irregularities on the components surface, which may be sites for crack initiation if the components were used in their as-built condition.

\subsection{Wire Fed Directed Energy Deposition}

Compared to blown powder processes, wire fed processes are advantageous due to higher deposition rates and the expense of suitable wire is lower than titanium powders [21]. One manufacturer who has adopted a wire fed DED process in their manufacturing process is Norsk Titanium. Their process involves the implementation of a wire DED processes for the manufacture of 
a structural aerospace component used on the Boeing 787 Dreamliner [64]. In this application, their Rapid Plasma Deposition ${ }^{\mathrm{TM}}$ process is used to build the part shown in Figure 6a, which is then milled on a five-axis CNC machining centre to produce the finished component.

Wire + Arc Additive Manufacturing (WAAM) is another technology which employs wire DED for the manufacture of large scale titanium alloy components [65]. The process, which is being developed in the UK by Cranfield University, uses an electric arc heat source and has been used to manufacture a variety of NNS parts such as the Ti-6Al-4V landing gear assembly shown in Figure 6b. When manufacturing large scale components such as these, the material saving benefits of metal AM are most significant. The implementation of the WAAM process to manufacture the part shown in Figure $6 \mathrm{~b}$, for example, offers material savings of $220 \mathrm{~kg}$. DED processes are some of the first instances where an AM process has been used to manufacture structural titanium aerospace components and these examples highlight the promising advancements of metal AM for the production parts which can meet the material property requirements for these types of applications.
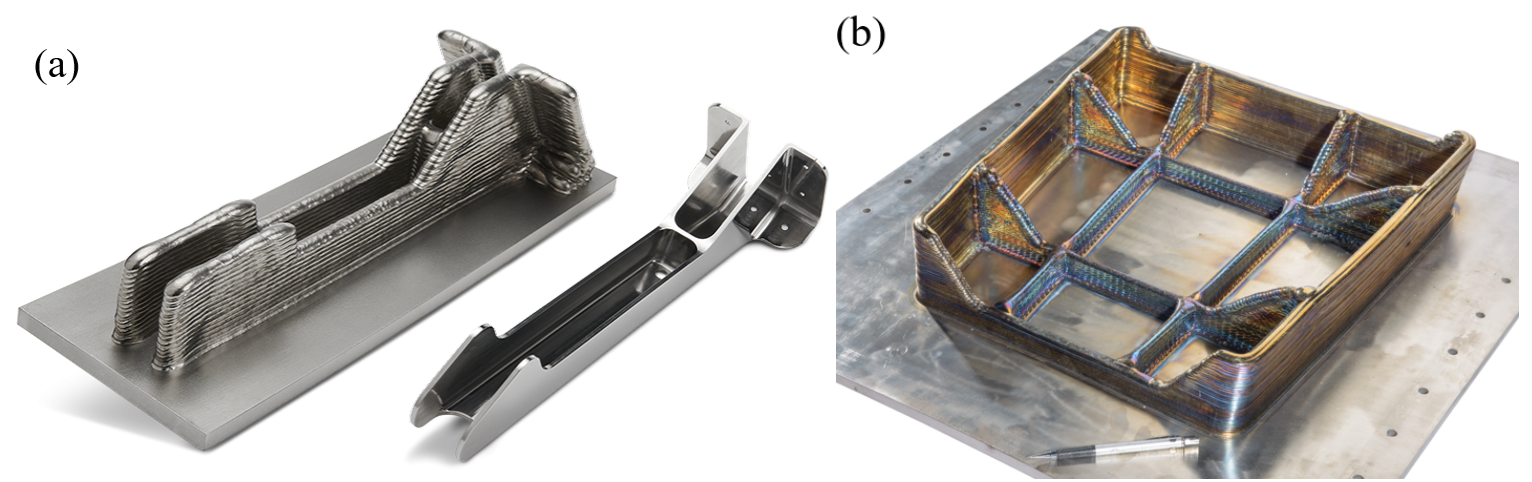

Figure 6. Titanium components manufactured by wire additive processes: (a) Boeing 787 structural component manufactured by Norsk Titanium's Rapid Plasma Deposition ${ }^{\text {TM }}$ process; and (b) Bombardier external landing gear assembly manufactured by the WAAM process at Cranfield University. Images in $(\boldsymbol{a}, \boldsymbol{b})$ reproduced with permission from Norsk Titanium [64] and Cranfield University [66], respectively.

The promising capabilities of wire based DED processes and the limitations of part resolution and surface finish, which necessitate more post-process machining than other AM processes, has led to the development of hybrid platforms which incorporate both DED additive with subtractive machining capabilities in a single machine tool [67]. Platforms such as the DMG Mori Seiki Lasertec 65 3D (DED/5-axis CNC machining) and NT 4300 3D (DED/CNC mill-turn) are examples of such machine tools. The development of such platforms offers manufacturers the ability to add and remove material with greater flexibility than what is currently available. Furthermore, these machines offer the potential to carry out both the additive and subtractive processes within closed loop control systems that use part measurements to influence process control and therefore can manufacture components with a high level of precision and automation. There is still however a limited understanding of the machining challenges specific to DED components and more work needs to be carried out in this area before manufacturers will have the confidence to replace conventional processes with this technology.

The challenges apparent during the post-process machining of Ti-6AL-4V parts produced by the LMwD method were investigated by Oyelola et al. [60,68]. In one of these studies they found that a $\beta$ heat treatment of the LMwD material resulted in a workpiece which was less challenging to machine than when attempting to machine the material in its as-built condition. The coarsening of the fine grained $\alpha$ laths, which occurred due to the heat treatment, was responsible for altering the mechanical properties of the material and resulted in a reduction of the material's hardness. The consequence of this effect was reduced cutting forces when machining material which had undergone the heat treatment. Periodicity of mechanical properties occurring in the build direction is common in DED materials due to the thermal effects that occur during reheating layers of the part as subsequent layers are deposited [21]. The effect of this periodicity on the material's hardness was found to contribute to 
higher cutting forces when machining LMwD compared to wrought material [68]. In the same study, they found that the poor dimensional accuracy of parts built using LMwD resulted in workpieces with significant run-out. Therefore, greater depths of cut were necessary to achieve steady-state cutting conditions when removing the outer layer of the component. Additionally, the wavy surface of the as-built part, a feature inherent with parts built using wire DED due to the layer on layer build process, also required higher depths of cut to avoid intermittent cutting.

For SMD processes, specifically the gas tungsten arc welding (GTAW) process, Hoye et al. [69] investigated both milling and drilling processes using SMD material. They found that AM Ti-6Al-4V was easier to machine than its wrought counterpart. This was evidenced by lower cutting forces when milling the material produced by the GTAW process, which was attributed to the lower hardness of the AM material. However, distortion and non-uniformity of the wall thickness of the parts produced by GTAW meant that, when milling, cutting forces were more variable during each pass than when machining the wrought parts. The drilling trials carried out showed that, even when the tool was fully engaged (the hole had reached its maximum diameter), steady state cutting forces were not achievable when drilling the AM material. This is indicative of the effects of periodicity in the properties of DED materials and shows similarities to the findings of Oyelola et al. [68].

\subsection{Consolidation of Powder into Wire}

Compared to metal powder, wire feedstock has significant advantages in terms of ease of handling for additive manufacturing processes. In addition, powder specifications on morphology and size mean that large volumes of powder can be surplus to requirements. In wire fed AM processes, 100\% of the material is used. This makes solid state processes such as continuous extrusion or Conform ${ }^{\mathrm{TM}}$ even more important in the future. Such severe plastic deformation processes can convert surplus powder, particulate or waste product, such as machining swarf, into a rod/wire form. This can then be further cold drawn into $<5 \mathrm{~mm}$ diameter wire for DED processes. Conform ${ }^{\mathrm{TM}}$ has been used since the 1970s for copper and aluminium rod feedstocks [70]. However, Thomas et al. [71] demonstrated that Conform ${ }^{\mathrm{TM}}$ can be adapted to convert CP-Ti powder into fully consolidated wire with a fine, equiaxed grain structure. Figure 7 shows a schematic of the Conform ${ }^{\mathrm{TM}}$ process used for the the production of CP-Ti wire from powder.
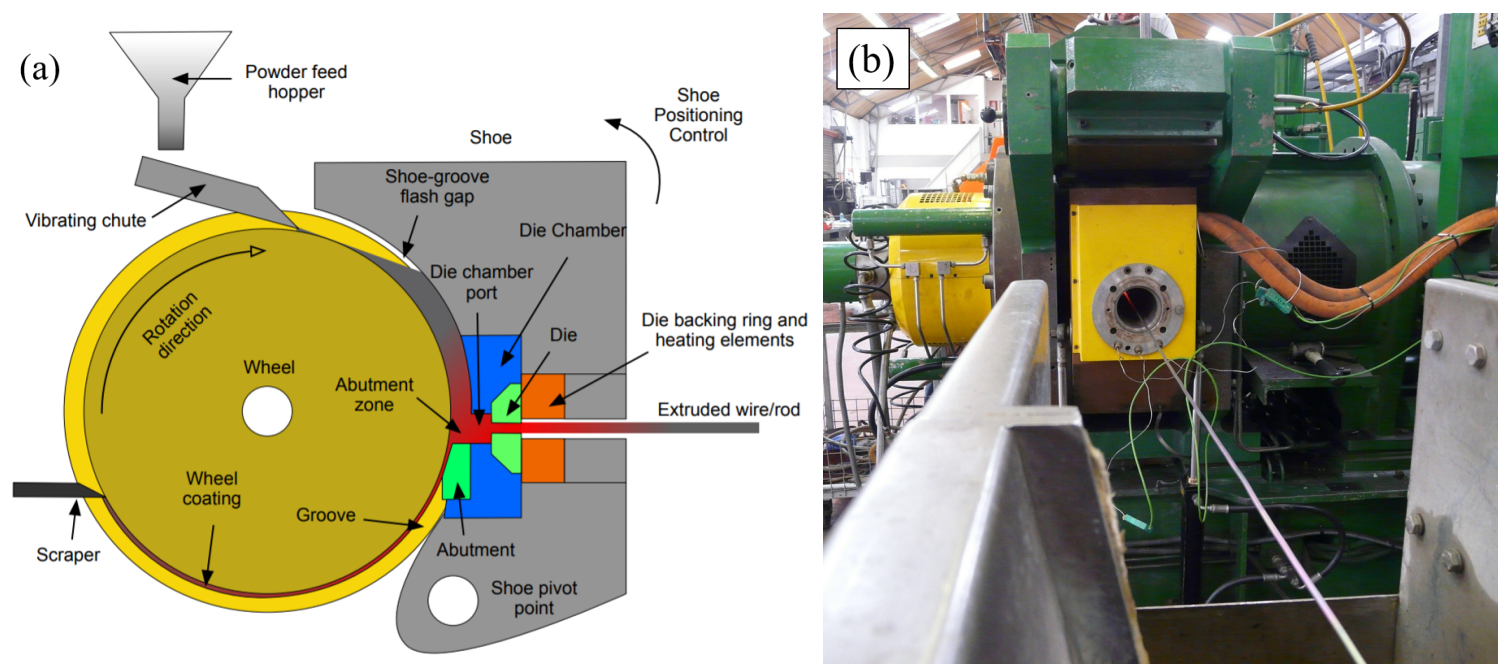

Figure 7. (a) Schematic representation of the Conform ${ }^{\mathrm{TM}}$ process. (b) Example of low oxygen, ductile, titanium alloy wire produced direct from powder [71]. 


\section{Hybrid Processing Routes}

Hybrid processing routes combine NNS manufacturing processes with an additional process step whereby preforms manufactured by a NNS process are deformed to enhance the mechanical properties of the material. The processes considered in this review achieve the deformation process by a single-step hot forging operation. This process is able to improve both the toughness and fatigue properties by grain refinement and porosity reduction.

\subsection{FAST-forge}

The FAST-forge process is a two-step solid-state hybrid manufacturing route being developed for the production NNS titanium alloy components. The initial step uses shaped field assisted sintering to consolidate titanium powder into a pre-forged billet. This is then followed by the second step, in which the FAST billet is then closed die hot forged to achieve a NNS part geometry [72]. This forging step improves the mechanical properties of the FAST titanium by refinement of the microstructure and allows for components to be manufactured with properties similar to those of conventional wrought products.

Research at the University of Sheffield has demonstrated the capabilities of FAST-forge in producing both Ti-6Al-4V and Ti-5553 specimens with a double truncated cone geometry in a laboratory setting [73]. In these instances, the material produced by the FAST-forge process showed similar microstructures to that of material forged using conventional methods. Further work has also been carried out demonstrating the capability of the process for manufacturing components with more intricate geometries such as the engine valve train rocker arms shown in Figure 1 and the eye-bolt forging shown in Figure 8a. In these types of applications, the economic advantages of alternative manufacturing methods, such as FAST-forge, both make the use of titanium components more viable for many industries and revitalise the long established UK closed die forging industry. For the automotive industry, in particular, processes such as FAST-forge present the potential for cost effective use of titanium alloys to achieve lighter weight products, which offer significant performance benefits compared to their traditionally steel counterparts.

(a)

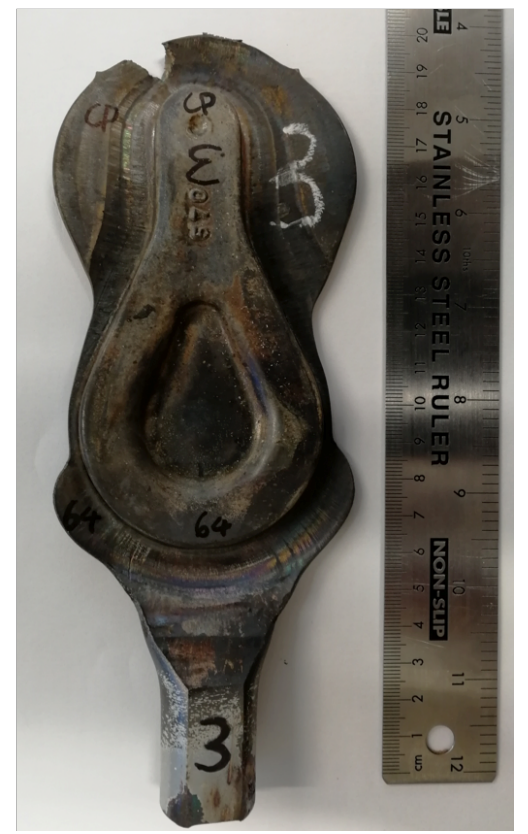

(b)

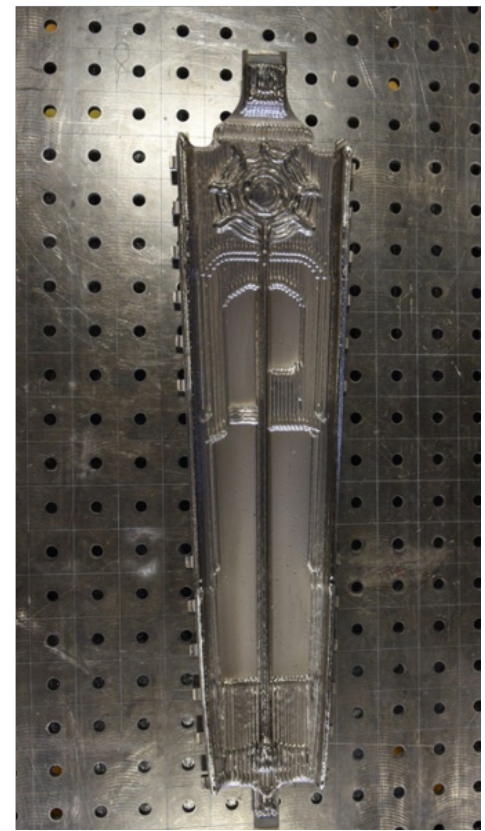

Figure 8. Titanium components manufactured by hybrid processing routes: (a) eye-bolt manufactured at the W.H. Tildesley, Wolverhampton and the University of Sheffield by the FAST-forge process; and (b) airframe structure manufactured by the Arconic Ampliforge ${ }^{\mathrm{TM}}$ hybrid AM-forging process. The image in (b) reproduced with permission from Arconic [74]. 


\subsection{Hybrid AM Technology for Forging}

Arconic's Ampliforge ${ }^{\mathrm{TM}}$ process is an emerging hybrid manufacturing technique that involves finish forging of a preform built using a wire or powder deposition type AM process (as represented by the schematic in Figure 3b. The AM built part is then machined to a pre-forging billet specification. The finish forging step achieves a NNS component geometry with enhanced material properties compared to conventional as-built wire deposition AM structures due to the microstructural refinement achieved by the forging process [75]. Figure $8 \mathrm{~b}$ shows a structural airframe part manufactured using the process. There is currently no published information concerning the mechanical properties of components built by the process, therefore it is difficult to suggest whether the enhancement of the properties of the AM material are sufficient enough to compete with those of conventionally forged components for these high strength, safety critical applications.

\section{Conclusions}

This review evaluates a selection of emerging NNS manufacturing processes suitable for the manufacture of titanium alloy components. Compared to conventional manufacturing routes, these processes can produce more cost effective NNS titanium alloy components with more efficient material utilisation. The review considers processes such as powder bed fusion and directed energy deposition AM processes, as well as hybrid processing routes. A comparison between the merits and challenges of each of these techniques is given, which suggests that powder bed fusion processes such as SLM and SEBM are well suited for the production of smaller, highly geometrically complex components such as medical implants. Conversely, direct energy deposition processes show more promise for the manufacture of larger scale components and have the potential to become more widely adopted for the manufacture of aerospace structures.

It is evident that, compared to wrought components, AM processes are less capable of producing components with the mechanical properties required in structurally critical applications. Issues such as the directional dependence of mechanical properties, as well as the poorer ductility and fatigue strength of AM, compared to wrought material, have influenced the use of post-process heat treatments and HIP of the as-built material. These have shown to be effective in alleviating some of these detrimental properties. Hybrid processing routes take post-processing of AM parts further, incorporating a hot forging step. This offers a potentially new method to manufacture high strength titanium aerospace structures which can compete with those only currently achievable by conventional forging processes.

This review also highlights the requirements for post-process machining of components produced by most NNS processes to achieve components that conform with both dimensional and surface finish tolerances. Future work is still necessary, however, to investigate processes which use a combination of NNS manufacturing followed by a post-process machining step to determine how parts that have been produced by NNS processes can be machined most effectively.

Funding: This review was supported by the EPSRC Industrial Doctorate Centre in Machining Science (EP/L016257/1) and MAPP the EPSRC Future Manufacturing Hub in Manufacture using Advanced Powder Processes (EP/P006566/1).

Acknowledgments: The authors acknowledge Ben Thomas, Nick Weston, Rob Snell, Everth Hernandez Nava, James Hunt, and Nikolaos Tapoglou at The University of Sheffield for useful discussions regarding NNS manufacture of titanium alloys.

Conflicts of Interest: The authors declare no conflict of interest. 


\section{References}

1. Jackson, M.; Boyer, R.R. Titanium and its Alloys: Processing, Fabrication and Mechanical Performance. Encycl. Aerosp. Eng. 2010. [CrossRef]

2. Klocke, F.; Arntz, K.; Klingbeil, N.; Schulz, M. Wire-based laser metal deposition for additive manufacturing of TiAl6V4: Basic investigations of microstructure and mechanical properties from build up parts. Proc. SPIE Laser 3D Manuf. IV 2017, 10095, 100950U. [CrossRef]

3. Jackson, M.; Dring, K. A review of advances in processing and metallurgy of titanium alloys. Mater. Sci. Technol. 2006, 22, 881-887. [CrossRef]

4. Fang, Z.Z.; Paramore, J.D.; Sun, P.; Chandran, K.S.; Zhang, Y.; Xia, Y.; Cao, F.; Koopman, M.; Free, M. Powder metallurgy of titanium-Past, present, and future. Int. Mater. Rev. 2018, 63, 407-459. [CrossRef]

5. Nazari, K.A.; Rahman Rashid, R.A.; Palanisamy, S.; Xia, K.; Dargusch, M.S. A novel Ti-Fe composite coating deposited using laser cladding of low cost recycled nano-crystalline titanium powder. Mater. Lett. 2018, 229, 301-304. [CrossRef]

6. Qi, Y.; Timokhina, I.B.; Shekhter, A.; Sharp, K.; Lapovok, R. Optimization of upcycling of Ti-6Al-4V swarf. J. Mater. Process. Technol. 2018, 255, 853-864. [CrossRef]

7. Shi, Q.; Tse, Y.Y.; Higginson, R.L. Microstructure and texture development during solid consolidation recycling of Ti-6Al-4V. Mater. Charact. 2019, 147, 223-232. [CrossRef]

8. Peter, W.H.; Yamamoto, Y. Near Net Shape Manufacturing of New , Low Cost Titanium Powders for Industry; Technical Report; Oak Ridge National Laboratory: Oak Ridge, YN, USA, 2013.

9. Agapovichev, A.; Sotov, A.; Kokareva, V.; Smelov, V. Possibilities and limitations of titanium alloy additive manufacturing. Matec Web Conf. 2018, 224, 01064. [CrossRef]

10. Bolzoni, L.; Ruiz-Navas, E.; Zhang, D.L.; Gordo, E. Modification of Sintered Titanium Alloys by Hot Isostatic Pressing. Key Eng. Mater. 2012, 520, 63-69. [CrossRef]

11. Kelto, C.; Kosmal, B.; Eylon, D.; Froes, F. Titan. Powder Metall. A Perspect. JOM 1980, 32, 17-25. [CrossRef]

12. German, R.M. Progress in titanium metal powder injection molding. Materials 2013, 6, 3641-3662. [CrossRef] [PubMed]

13. Eylon, D.; Froes, F.; Gardiner, R. Developments in Titanium Alloy Casting Technology. JOM 1983, 35, 35-47. [CrossRef]

14. Jackson, M. Superplastic forming and diffusion bonding of titanium alloys. In Superplastic Forminf of Advanced Metaillic Materials: Methods and Applications; Giuliano, G., Ed.; Woodhead Publishing Ltd.: Cambridge, UK, 2011.

15. Javaid, M.; Haleem, A. Additive manufacturing applications in medical cases : A literature based review. Alex. J. Med. 2018, 54, 411-422. [CrossRef]

16. Popov, V.V.; Gary, J.; Kovalevsky, M.k.A.; Dzhenzhera, G.; Strokin, E.; Kolomiets, A.; Ramon, J.; Muller-kamskii, G. Design and 3D-printing of titanium bone implants: Brief review of approach and clinical cases. Biomed. Eng. Lett. 2018, 8, 337-344. [CrossRef] [PubMed]

17. Nickels, L. AM and aerospace: An ideal combination. Met. Powder Rep. 2015, 70, 300-303. [CrossRef]

18. Neikter, M.; Åkerfeldt, P.; Pederson, R.; Antti, M.L. Microstructure characterisation of Ti-6Al-4V from different additive manufacturing processes. IOP Conf. Ser. Mater. Sci. Eng. 2017, 258. [CrossRef]

19. Oyelola, O.; Crawforth, P.; M'Saoubi, R.; Clare, A.T. Machining of Additively Manufactured Parts: Implications for Surface Integrity. Procedia CIRP 2016, 45, 119-122. [CrossRef]

20. Miura, H. Direct laser forming of titanium alloy powders for medical and aerospace applications. KONA Powder Part. J. 2015, 32, 253-263. [CrossRef]

21. Yilmaz, O.; Ugla, A.A. Shaped metal deposition technique in additive manufacturing: A review. Proc. Inst. Mech. Eng. Part B J. Eng. Manuf. 2016, 230, 1781-1798. [CrossRef]

22. Gorsse, S.; Hutchinson, C.; Gouné, M. Additive manufacturing of metals: A brief review of the characteristic microstructures and properties of steels , Ti-6Al-4V and high-entropy alloys. Sci. Technol. Adv. Mater. 2017, 18, 584-610. [CrossRef]

23. Qian, M.; Xu, W.; Brandt, M.; Tang, H.P. Additive manufacturing and postprocessing of Ti-6Al-4V for superior mechanical properties. MRS Bull. 2016, 41, 775-783. [CrossRef] 
24. Tammas-Williams, S.; Zhao, H.; Léonard, F.; Derguti, F.; Todd, I.; Prangnell, P.B. XCT analysis of the influence of melt strategies on defect population in Ti-6Al-4V components manufactured by Selective Electron Beam Melting. Mater. Charact. 2015, 102, 47-61. [CrossRef]

25. Wang, F.; Williams, S.; Colegrove, P.; Antonysamy, A.A. Microstructure and mechanical properties of wire and arc additive manufactured Ti-6Al-4V. Metall. Mater. Trans. A Phys. Metall. Mater. Sci. 2013, 44, 968-977. [CrossRef]

26. Arias-González, F.; del Val, J.; Comesaña, R.; Penide, J.; Lusquiños, F.; Quintero, F.; Riveiro, A.; Boutinguiza, M.; Gil, F.J.; Pou, J. Microstructure and crystallographic texture of pure titanium parts generated by laser additive manufacturing. Met. Mater. Int. 2018, 24, 231-239. [CrossRef]

27. Gong, X.; Lydon, J.; Cooper, K.; Chou, K. Beam speed effects on Ti-6Al-4V microstructures in electron beam additive manufacturing. J. Mater. Res. 2014, 29, 1951-1959, [CrossRef]

28. Liu, Q.; Wang, Y.; Zheng, H.; Tang, K.; Ding, L.; Li, H.; Gong, S. Microstructure and mechanical properties of LMD-SLM hybrid forming Ti6Al4V alloy. Mater. Sci. Eng. A 2016, 660, 24-33. [CrossRef]

29. Neikter, M.; Åkerfeldt, P.; Pederson, R.; Antti, M.L.; Sandell, V. Microstructural characterization and comparison of Ti-6Al-4V manufactured with different additive manufacturing processes. Mater. Charact. 2018, 143, 68-75. [CrossRef]

30. Simonelli, M.; Tse, Y.Y.; Tuck, C. On the texture formation of selective laser melted Ti-6Al-4V. Metall. Mater. Trans. A Phys. Metall. Mater. Sci. 2014, 45, 2863-2872. [CrossRef]

31. Cunningham, R.; Narra, S.P.; Ozturk, T.; Beuth, J.; Rollett, A.D. Evaluating the Effect of Processing Parameters on Porosity in Electron Beam Melted Ti-6Al-4V via Synchrotron X-ray Microtomography. JOM 2016, 68, 765-771. [CrossRef]

32. Lewandowski, J.J.; Seifi, M. Metal Additive Manufacturing: A Review of Mechanical Properties. Annu. Rev. Mater. Res. 2016, 46, 151-186. [CrossRef]

33. Brandl, E.; Palm, F.; Michailov, V.; Viehweger, B.; Leyens, C. Mechanical properties of additive manufactured titanium (Ti-6Al-4V) blocks deposited by a solid-state laser and wire. Mater. Des. 2011, 32, 4665-4675. [CrossRef]

34. Bian, L.; Thompson, S.M.; Shamsaei, N. Mechanical Properties and Microstructural Features of Direct Laser-Deposited Ti-6Al-4V. JOM 2015, 67, 629-638. [CrossRef]

35. Baufeld, B.; Van Der Biest, O.; Gault, R. Microstructure of Ti-6Al-4V specimens produced by shaped metal deposition. Int. J. Mater. Res. 2009, 100, 1536-1542. [CrossRef]

36. Kasperovich, G.; Hausmann, J. Improvement of fatigue resistance and ductility of TiAl6V4 processed by selective laser melting. J. Mater. Process. Technol. 2015, 220, 202-214. [CrossRef]

37. Leung, C.L.A.; Marussi, S.; Towrie, M.; Atwood, R.C.; Withers, P.J.; Lee, P.D. The effect of powder oxidation on defect formation in laser additive manufacturing. Acta Mater. 2019, 166, 294-305. [CrossRef]

38. Caballero, A.; Ding, J.; Bandari, Y.; Williams, S. Oxidation of Ti-6Al-4V During Wire and Arc Additive Manufacture. 3D Print. Addit. Manuf. 2019, 6, 29-37. [CrossRef]

39. Bermingham, M.J.; Thomson-Larkins, J.; St John, D.H.; Dargusch, M.S. Sensitivity of Ti-6Al-4V components to oxidation during out of chamber Wire and Arc Additive Manufacturing. J. Mater. Process. Technol. 2018, 258, 29-37. [CrossRef]

40. Na, T.W.; Kim, W.R.; Yang, S.M.; Kwon, O.; Park, J.M.; Kim, G.H.; Jung, K.H.; Lee, C.W.; Park, H.K.; Kim, H.G. Effect of laser power on oxygen and nitrogen concentration of commercially pure titanium manufactured by selective laser melting. Mater. Charact. 2018, 143, 110-117. [CrossRef]

41. Karlsson, J.; Norell, M.; Ackelid, U.; Engqvist, H.; Lausmaa, J. Surface oxidation behavior of Ti-6Al-4V manufactured by Electron Beam Melting (EBM $\left.{ }^{\circledR}\right)$. J. Manuf. Process. 2015, 17, 120-126. [CrossRef]

42. Tang, H.P.; Qian, M.; Liu, N.; Zhang, X.Z.; Yang, G.Y.; Wang, J. Effect of Powder Reuse Times on Additive Manufacturing of Ti-6Al-4V by Selective Electron Beam Melting. JOM 2015, 67, 555-563. [CrossRef]

43. Sun, Y.; Aindow, M.; Hebert, R.J. The effect of recycling on the oxygen distribution in Ti-6Al-4V powder for additive manufacturing. Mater. High Temp. 2018, 35, 217-224. [CrossRef]

44. Olakanmi, E.O.; Cochrane, R.F.; Dalgarno, K.W. A review on selective laser sintering/melting (SLS/SLM) of aluminium alloy powders: Processing, microstructure, and properties. Prog. Mater. Sci. 2015, 74, 401-477. [CrossRef]

45. Uhlmann, E.; Kersting, R.; Klein, T.B.; Cruz, M.F.; Borille, A.V. Additive Manufacturing of Titanium Alloy for Aircraft Components. Procedia CIRP 2015, 35, 55-60. [CrossRef] 
46. Caiazzo, F.; Cardaropoli, F.; Alfieri, V.; Sergi, V.; Cuccaro, L. Experimental analysis of selective laser melting process for Ti-6Al-4V turbine blade manufacturing. In Proceedings of the XIX International Symposium on High-Power Laser Systems and Applications 2012, Istanbul, Turkey, 30 January 2013; Volume 8677, p. $86771 \mathrm{H}$. [CrossRef]

47. Harun, W.; Manam, N.; Kamariah, M.; Sharif, S.; Zulkifly, A.; Ahmad, I.; Miura, H. A review of powdered additive manufacturing techniques for Ti-6Al-4V biomedical applications. Powder Technol. 2018, 331, 74-97. [CrossRef]

48. Schulze, C.; Weinmann, M.; Schweigel, C.; Keßler, O.; Bader, R. Mechanical Properties of a Newly Additive Manufactured Implant Material Based on Ti-42Nb. Materials 2018, 11, 124. [CrossRef] [PubMed]

49. Fousová, M.; Vojt, D.; Jablonská, E.; Fojt, J. Promising characteristics of gradient porosity Ti-6Al-4V alloy prepared by SLM process. J. Mech. Behav. Biomed. Mater. 2017, 69, 368-376. [CrossRef]

50. Shunmugavel, M.; Polishetty, A.; Nomani, J.; Goldberg, M.; Littlefair, G. Metallurgical and Machinability Characteristics of Wrought and Selective Laser Melted Ti-6Al-4V. J. Metall. 2016, 2016, 1-10. [CrossRef]

51. Milton, S.; Morandeau, A.; Chalon, F.; Leroy, R. Influence of Finish Machining on the Surface Integrity of Ti6Al4V Produced by Selective Laser Melting. Procedia CIRP 2016, 45, 127-130. [CrossRef]

52. Khorasani, A.M.; Gibson, I.; Goldberg, M.; Littlefair, G. A comprehensive study on surface quality in 5-axis milling of SLM Ti-6Al-4V spherical components. Int. J. Adv. Manuf. Technol. 2018, 94, 3765-3784. [CrossRef]

53. In-situ Quality Assurance with QMmeltpool 3D from Concept Laser. Available online: https:/ / www.conceptlaser.de/contact_usa/in-situ-quality-assurance-with-qmmeltpool-3d-from-concept-laser/ (accessed on 14 May 2019).

54. Körner, C. Additive manufacturing of metallic components by selective electron beam melting a review. Int. Mater. Rev. 2016, 6608. [CrossRef]

55. Zhang, L.c.; Liu, Y.; Li, S.; Hao, Y. Additive Manufacturing of Titanium Alloys by Electron Beam Melting: A Review. Adv. Eng. Mater. 2018, 20, 1700842. [CrossRef]

56. Rawal, S.; Brantley, J.; Karabudak, N. Additive manufacturing of Ti-6Al-4V alloy components for spacecraft applications. In Proceedings of the 6th International Conference on Recent Advances in Space Technologies (RAST 2013), Istanbul, Turkey, 12-14 June 2013 ; pp. 5-11. [CrossRef]

57. Sartori, S.; Moro, L.; Ghiotti, A.; Bruschi, S. On the tool wear mechanisms in dry and cryogenic turning Additive Manufactured titanium alloys. Tribiol. Int. 2017, 105, 264-273. [CrossRef]

58. Palanisamy, C. A review of additive manufacturing of $\alpha-\beta$ Ti alloy components through selective laser melting and laser metal deposition. J. Eng. Sci. Technol. 2018, 13, 790-812.

59. Saboori, A.; Gallo, D.; Biamino, S.; Fino, P.; Lombardi, M. An Overview of Additive Manufacturing of Titanium Components by Directed Energy Deposition : Microstructure and Mechanical Properties. Appl. Sci. 2017, 7, 883. [CrossRef]

60. Oyelola, O.; Crawforth, P.; M'Saoubi, R.; Clare, A.T. Machining of functionally graded Ti6Al4V/ WC produced by Directed Energy Deposition. Addit. Manuf. 2018, 24, 20-29. [CrossRef]

61. Baufeld, B.; Van Der Biest, O.; Gault, R.; Ridgway, K. Manufacturing Ti-6Al-4V components by Shaped Metal Deposition: Microstructure and mechanical properties. IOP Conf. Ser. Mater. Sci. Eng. 2011, 26, S106-S111. [CrossRef]

62. Bermingham, M.; Nicastro, L.; Kent, D.; Chen, Y.; Dargusch, M. Optimising the mechanical properties of Ti-6Al-4V components produced by wire and arc additive manufacturing with post-process heat treatments. J. Alloys Compd. 2018. [CrossRef]

63. Clark, D.; Whittaker, M.T.; Bache, M.R. Microstructural characterization of a prototype titanium alloy structure processed via direct laser deposition (DLD). Metall. Mater. Trans. B Process. Metall. Mater. Process. Sci. 2012, 43, 388-396. [CrossRef]

64. Norsk Titanium. Available online: https:/ /www.norsktitanium.com/ (accessed on 15 May 2019).

65. Williams, S.W.; Martina, F.; Addison, A.C.; Ding, J.; Pardal, G.; Colegrove, P. Wire + Arc Additive Manufacturing. Mater. Sci. Technol. 2015, 32, 641-647. [CrossRef]

66. WAAM Demo Parts. Available online: https:/ / waammat.com/about/demo-parts (accessed on 14 May 2019).

67. Flynn, J.; Shokrani, A.; Newman, S.T.; Dhokia, V. Hybrid Additive and Subtractive Machine Tools- Research and Industrial Developments. Int. Mach. Tools Manuf. 2015. [CrossRef]

68. Oyelola, O.; Crawforth, P.; M'Saoubi, R.; Clare, A.T. On the machinability of directed energy deposited Ti6Al4V. Addit. Manuf. 2018, 19, 39-50. [CrossRef] 
69. Hoye, N.; Cuiuri, D.; Rashid, R.A.R.; Palanisamy, S. Machining of GTAW additively manufactured Ti-6Al-4V structures. Int. J. Adv. Manuf. Technol. 2018, 99, 313-326. [CrossRef]

70. Pardoe, J.A. 'Conform' Continuous Extrusion of Metal Powders into Products for Electrical Industry: Development Experience. Powder Metall. 1979, 22, 22-28. [CrossRef]

71. Thomas, B.M.; Derguti, F.; Jackson, M. Continuous extrusion of a commercially pure titanium powder via the Conform process. Mater. Sci. Technol. 2017, 33, 899-903. [CrossRef]

72. Weston, N.S.; Jackson, M. FAST-forge-A new cost-effective hybrid processing route for consolidating titanium powder into near net shape forged components. J. Mater. Process. Technol. 2017, 243, 335-346. [CrossRef]

73. Calvert, E.; Wynne, B.; Weston, N.; Tudball, A.; Jackson, M. Thermomechanical processing of a high strength metastable beta titanium alloy powder, consolidated using the low-cost FAST-forge process. J. Mater. Process. Technol. 2018, 254, 158-170. [CrossRef]

74. Arconic Announces Airbus 3D Printing Research Agreement. Available online: https://www.aero-mag. com/arconic-announces-airbus-3d-printing-research-agreement/ (accessed on 14 May 2019).

75. Chastka, M.; Alman, E.; Satoh, G.; Bodily, B. Arconic WDED Additive Manufacturing and the Ampliforge Process. In Proceedings of the Forging Industry Technical Conference, Long Beach , CA, USA, 11-12 September 2018.

(C) 2019 by the authors. Licensee MDPI, Basel, Switzerland. This article is an open access article distributed under the terms and conditions of the Creative Commons Attribution (CC BY) license (http://creativecommons.org/licenses/by/4.0/). 